\title{
Multiattribute Supplier Selection Using Fuzzy Analytic Hierarchy Process
}

\author{
Serhat Aydin* \\ Aeronautics and Space Technologies Institute, Turkish Air Force Academy \\ Yesilyurt, Bakirkoy, Istanbul 34149, Turkey \\ Cengiz Kahraman \\ Industrial Engineering Department, Istanbul Technical University \\ Macka, Besiktas 34367, Turkey \\ E-mail: kahramanc@itu.edu.tr \\ Received: 06-01-2010 \\ Accepted: 19-03-2010
}

\begin{abstract}
Supplier selection is a multiattribute decision making (MADM) problem which contains both qualitative and quantitative factors. Supplier selection has vital importance for most companies. The aim of this paper is to provide an AHP based analytical tool for decision support enabling an effective multicriteria supplier selection process in an air conditioner seller firm under fuzziness. In this article, the Analytic Hierarchy Process (AHP) under fuzziness is employed for its permissiveness to use an evaluation scale including linguistic expressions, crisp numerical values, fuzzy numbers and range numerical values. This scale provides a more flexible evaluation compared with the other fuzzy AHP methods. In this study, the modified AHP was used in supplier selection in an air conditioner firm. Three experts evaluated the suppliers according to the proposed model and the most appropriate supplier was selected. The proposed model enables decision makers select the best supplier among supplier firms effectively. We confirm that the modified fuzzy AHP is appropriate for group decision making in supplier selection problems.
\end{abstract}

Keywords: Fuzzy, AHP, group decision making, supplier selection, linguistic scale.

\section{Introduction}

Supplier selection has a considerable role in achieving the objective of supply chain network. Many studies show that it is the most significant step which determines the success of the supply chain. ${ }^{1}$ Supplier selection involves the selection of the best supplier from a pool of existing suppliers according to predefined set of criteria. ${ }^{2}$

Due to recent progress in industrial technology, demand toward high quality products has increased prices. This trend enhanced the importance of product quality and production methods in companies' perspective, as well as traditionally sought factors such as price. ${ }^{3}$ Therefore companies need to select the best supplier for attaining high quality products at lower cost which leads to higher customer satisfaction in this competitive environment

Supplier selection is one of the major multiattribute decision making (MADM) problems. ${ }^{4}$ As most of the MADM problems, supplier selection involves many complexities such as evaluation of multiple and conflicting criteria, divergence of decision makers or difficulties in data collection.

\footnotetext{
${ }^{*}$ Corresponding author: s.aydin $@$,hho.edu.tr, Tel: +90212 6632490
} 
In the literature, many methods including integrated methodologies have been used to overcome complexities of supplier selection problems. ${ }^{5}$ Among these methods we can count Multiattribute Utility Analysis $\left(\operatorname{Min}^{6}\right)$, ELECTRE (Boer et al. $^{7}$ ), mixed integer non-linear programming (Ghodsypour and O'Brien ${ }^{8}$ ), goal programming (Karpak et al. ${ }^{9}$ ), linear programming (Talluri and Narasimhan ${ }^{10}$ ), decision trees $\left(\mathrm{Oz}\right.$ and Baykoc $\left.^{11}\right)$, pattern recognition method (Cedimoglu and Tunacan ${ }^{12}$ ), multipurpose programming (Narasimhan et al. ${ }^{13}$ ), integer programming (Hong et al. ${ }^{14}$ ), data envelopment analysis $\left(\right.$ Saen $^{15}$ ), TOPSIS (Boran et al. ${ }^{16}$ ), PROMETHEE (Dagdeviren and Eraslan ${ }^{17}$ ), Analytic Network Process (ANP) (Gencer and Gurpinar ${ }^{18}$ ), multi-purpose programming (Liao and Rittscher ${ }^{19}$ ), fuzzy genetic algorithms (Junyan et al. ${ }^{20}$ ), fuzzy case based reasoning (Faez et al. ${ }^{21}$ ), artificial neutral networks (Ha and Krishan ${ }^{22}$ ).

In addition to the above methods, several authors tended to apply Analytic Hierarchy Process (AHP) which was commonly used in MADM. Xia and $\mathrm{Wu}^{23}$ used AHP method for supplier selection with multiple criteria in volume discount environments. Chan et $\mathrm{al}^{24}$ developed an interactive selection model with AHP to facilitate decision makers in selecting suppliers. Hou and $\mathrm{Su}^{25}$ developed an AHP-based decision support system for the supplier selection problem in a mass customization environment. Kahraman et al. ${ }^{26}$ used fuzzy logic and AHP methods for supplier selection in catering industry. Cercioglu et al. ${ }^{27}$ used DempsterShafer AHP model in supplier evaluation. Kubat and Yuce $^{28}$ formed fuzzy AHP to evaluate the suppliers' weights and solved the problem with genetic algorithm. The authors emphasized that, AHP allows obtaining reasonable outcomes with high applicability compared to other methods.

AHP is an analytical method which can be applied to problems having multiple alternatives and multiple criteria. AHP doesn't require complex mathematical operations. It is based on developing synthesized pairwise comparison matrix and identifying priority vector. Classic AHP uses integers in computing importance scale, however, real-world problems involve substantial vagueness and uncertainty, which necessitates using fuzzy numbers. ${ }^{29}$ Therefore, AHP and fuzzy logic were combined and transformed into an integrated model called fuzzy AHP. It was considered that fuzzy AHP can be effective in solving supplier selection problems which require a fuzzy approval due to inherent uncertainties inherent in selecting the best supplier. In this respect, the current study aimed to represent application of fuzzy AHP in supplier selection. We preferred Zeng et al.' ${ }^{29}$ method to other modified AHP methods due to its ability to handle experts knowledge, judgments, historical data about supplier.

In this research, the method proposed by Zeng et al. ${ }^{29}$ was applied to the firm according to predefined criteria. The priority values for each alternative supplier were calculated. The alternative with the highest score was selected as the best supplier firm.

The rest of this paper is organized as follows. Section 2 defines evaluation criteria for the supplier selection. Fuzzy sets and fuzzy numbers are introduced in Section 3. Next, Section 4 describes modified AHP. Subsequently a numerical illustration is presented in Section 5. Sensitivity analysis is performed in Section 6. Finally, conclusions are presented in Section 7.

\section{Evaluation Criteria for Supplier Selection}

In the literature, number of criteria were proposed for supplier selection. In our study, we determined the most suitable criteria for the firm's requirements. The main criteria and sub-criteria used to evaluate suppliers are illustrated in Table 1. The definitions of these criteria are as follows;

Cost: Cost is the one of the crucial factors in the procurement process. Supplier can give a low price, which seems preferable in monetary terms. However, whether the suppliers can provide the proper service that meets the company needs should be considered, as well as the price. This criterion has been used by many researchers such as: Nydick and Hill, ${ }^{30}$ Albanio and Garavelli, ${ }^{31}$ Lee, ${ }^{32}$ Bharadwaj. ${ }^{33}$

Service: The service factor incorporates subfactors that determine the service preference of the supplier. This criterion has been used by Hwang et al. ${ }^{34}$

On-time delivery: The supplier should maintain the delivery schedule determined by the firm. Verna and Pulman $^{35}$ and Ting ${ }^{36}$ used this criterion.

Warranty period and insurance: The warranty period that the supplier proposes for the goods should not be shorter than the period that the firm specifies in the technical specifications document. Lehman and $\mathrm{O}^{\prime}$ Shaughnessy $\mathrm{y}^{37}$ and $\mathrm{Xia}$ and $\mathrm{Wu}^{23}$ used this criterion. 
Repair turnround time: The supplier should return repaired goods within turnround time specified by the firm. This criterion has been used by Xia and $\mathrm{Wu}^{23}$

Information sharing: The supplier should be open to communication and negotiation. Chan et al. ${ }^{2}$ used this criterion in his study.

Availability in any time: Supplier should maintain the service in any time including weekends and holidays as necessary. This criterion was used in Kanan and Haq's ${ }^{38}$ study.

Distribution and storage facility: Distribution network and storages of the supplier how well that give us information about the company's status. Jayaraman et al. ${ }^{39}$ used this criterion.

Quality: The supplier should provide goods that conform to the requirement set by the firm. This criterion has been used in many studies; Siying et al., ${ }^{40}$ Weber et al. ${ }^{41}$

Conformance to specification: The goods delivered by the supplier should conform to the specifications given in the technical specification document. Chan et al. ${ }^{2}$ used this criterion in their study.

Product reliability: The supplier should deliver goods at different shipment in same quality. Thanaraksakul and Phruksaphanrat ${ }^{42}$ used this criterion in their study.

Quality assurance certification: The supplier should have quality assurance certification required by the firm. Zaim et al. ${ }^{43}$ and $\mathrm{Oz}$ and Baykoc ${ }^{11}$ used this criterion in their studies.

Product Defected rate: The defect rate encountered in the previous contracts the supplier. This criterion was used by $\mathrm{Xia}$ and $\mathrm{Wu}^{23}$.

Apparent Quality: The quality of the goods delivered by the suppliers should be acceptable when visually inspected. Stavropolous ${ }^{44}$ used this criterion in his research.

Supplier Firm: This criteria involves general information about the supplier. This criterion has been used in many studies; Zaim et al. ${ }^{43}$ Chan et al. ${ }^{41}$ Boer. ${ }^{7}$

Capacity: The supplier should provide the required amount of goods. Lehman and O'Shaughnessy, ${ }^{37}$ Jayaraman ${ }^{39}$ used this criterion in their studies.
Table 1. Criteria taken into account to select the best supplier.

\begin{tabular}{|l|l|}
\hline Main criterion & Sub-criteria \\
\hline Cost (C1) & \multicolumn{1}{|c|}{} \\
\hline Service (C2) & $\begin{array}{l}\text { On-time delivery (C21) } \\
\text { Warranty period and insurance (C22) } \\
\text { Repair turn round time (C23) } \\
\text { Information sharing (C24) } \\
\text { Whole year Availability (C25) } \\
\text { Distribution and storage facility (C26) }\end{array}$ \\
\hline Quality (C3) & $\begin{array}{l}\text { Conformance to specification (C31) } \\
\text { Product reliability (C32) } \\
\text { Quality assurance certification (C33) } \\
\text { Defected rate product (C34) } \\
\text { Apparent Quality (C35) }\end{array}$ \\
\hline Supplier Firm (C4) & $\begin{array}{l}\text { Capacity (C41) } \\
\text { Experience and performance (C42) } \\
\text { Reputation (C43) } \\
\text { Geographical location (C44) } \\
\text { Financial status (C45) }\end{array}$ \\
\hline Flexibility (C5) & $\begin{array}{l}\text { Changing order volumes(C51) } \\
\text { Changing mix of ordered items (C52) }\end{array}$ \\
\hline
\end{tabular}

Experience and Performance: The supplier's experience in the market and performance in the previous contracts are combined into a single criterion. Cercioglu et al. ${ }^{27}$ used this criterion.

Reputation: The supplier should have a good reputation in the market. This criterion was used by Zaim. $^{43}$

Geographical location: The supplier should be located in an acceptable distance from the firm such that product delivery time can be minimized. This criterion was used by Siying et al. ${ }^{40}$ and Barla ${ }^{45}$.

Financial status: The supplier should maintain delivery of goods under all financial conditions. This criterion has been used by many researchers: Boer et al., ${ }^{7}$ Lehman and O'Shaughnessy. ${ }^{37}$

Flexibility: The supplier should adjust to the changing demands as necessary. This criterion has been used by Lehman and O'Shaughnessy, ${ }^{37}$ Barla. ${ }^{45}$

Respond to the demands of the changing order volumes: This criterion has been used by Chan and Chan. ${ }^{46}$

Respond to the demand of the changing mix of ordered items: Chan and Chan, ${ }^{46}$ used this criterion in their study. 


\section{Fuzzy Sets and Fuzzy Numbers}

The fuzzy set theory was introduced by Zadeh ${ }^{47}$ for solving problems in which descriptions of activities and observations are imprecise, vague, and uncertain. The term "fuzzy" refers to the situation in which there are no well-defined boundaries of the set of activities or observations. $^{48}$

The fuzzy set theory was adapted to the rationality of uncertainty. Representing vague data was the major contribution of the fuzzy set theory. ${ }^{26}$ Unfortunately, decision makers don't generally have sufficient data to perform decision analysis. Therefore decision makers should rely on expert's knowledge and judgment while modeling decision analysis problems. The fuzzy set theory is concerned with vagueness in human thoughts and perception in order to obtain quantitative data in case of imprecision and uncertainty. ${ }^{49}$

A fuzzy set is a class of objects with a continuum of membership grades. A membership function, which assigns a grade of membership to each object, is associated with each fuzzy set. Usually, the membership grades are in $[0,1] .^{48}$ The fuzzy set is usually denoted as

$$
\widetilde{A=}=\left\{\left(x, \mu_{a}(x)\right) x \in X\right\}
$$

where $\mathrm{X}$ is a collection of objects denoted by $\mathrm{x}$ and $\mu_{a}(x)$ is the membership function.

It is possible to convert a "crisp" definition into a "fuzzified" one by generalizing the concept of a crisp set into a fuzzy set with blurred boundaries. This can be applied to any methodology or theory. On the other hand, the fuzzy set theory implements grouping of data with loosely defined boundaries. Real world problems have many imprecision in the variables and parameters measured and processed for the application. Extending crisp analysis methods to fuzzy techniques has the benefit of solving real world problems effectively. To achieve this benefit, linguistic variables are used as a critical aspect of some fuzzy logic applications. If a variable can take words in naturally languages as its value, it is called a linguistic variable, where the words such as "good", "mediocre", and "bad" are characterized by fuzzy sets defined in the universe of discourse in which the variables is defined. ${ }^{50}$

Fuzzy sets include fuzzy numbers in computational efforts. Fuzzy numerical calculations need cumbersome effort. Thus there are special fuzzy numbers for easy calculation: Triangular fuzzy numbers by Laarhoven and Pedrycz,${ }^{51}$ trapezoidal fuzzy numbers by Buckley, ${ }^{52}$ and L-R numbers fuzzy numbers by Dubois And Prade. ${ }^{53}$ Since the method proposed by Zeng et al. ${ }^{29}$ uses standardized trapezoidal fuzzy numbers (STFN), trapezoidal fuzzy numbers are explained below.

A fuzzy number is a special fuzzy set $F=\{(x, \mu(x)), x \in R\}, \quad R:-\infty<x<+\infty$ and its membership function $\mu(x): R[0,1]$, where $\mathrm{x}$ represents supplier alternatives. A trapezoidal fuzzy number $\tilde{A}=(a, b, c, d)$, is a normal and convex fuzzy set on the real line with a piecewise continuous membership function, as illustrated in Figure 1. The following properties are valid for trapezoidal membership function

(i) $\mu(x)=0$ for every $x \in(-\infty, a) \cup(d, \infty)$

(ii) $\mu$ is increasing on $[a, b]$ and decreasing on $[c, d]$

(iii) $\mu(a)=\mu(d)=0$ and $\mu(x)=1$, for every $x \in[b, c]$

The membership function of a trapezoidal fuzzy number is given by

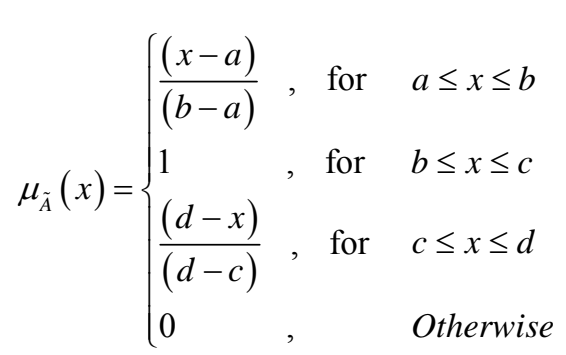

The cases $a=-\infty$ and $d=+\infty$ are admitted and then, the fuzzy number will be, by the left or by the right, asymptotically zero, so its support will not be bounded.

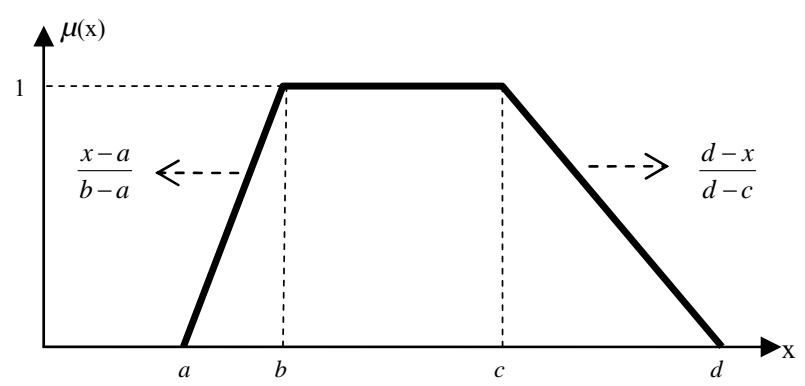

Fig. 1. Membership function of STFN 


\section{Fuzzy AHP}

AHP, developed by Saaty ${ }^{54}$ in 1980, addresses how to determine the relative importance of a set of activities in a multicriteria decision problem. The process makes it possible to incorporate judgments on intangible qualitative criteria alongside tangible quantitative criteria. ${ }^{55}$ It is a hierarchy process to solve complex problems involving multiple attributes by constructing the problem in to the goal, attribute and alternatives for decision maker. This method is based on pairwise comparisons between criteria and alternatives. ${ }^{56}$

A pairwise comparison matrix yields weights which are derived from the set of decision maker's judgments. Data are gathered by interviewing the decision makers using a questionnaire with the "1-9 scale" proposed by Saaty $^{54}$. In this scale, while comparing two factors, if "A" factor has an equal importance with "B" it has a value of " 1 "; if it has a moderately more importance it takes the value of " 3 ", if it has a stronger importance it takes the value of " 5 "; if it has very strong importance over B, it takes the value of " 7 ", if it is extremely important, it takes the value of " 9 ". The remaining 2,4,6,8 values are used to settle if the preference values are close to each other. According to Zeng et al. ${ }^{29}$, using this kind of a scale has lots of disadvantages. First of all, the experts participating in the questionnaire can have varying judgments. For instance, an expert can argue that " $B$ " factor has an importance over " $A$ " between the values of 3-5 instead of making a crisp scale decision. Furthermore, expert can avoid making a comparison because of the lack of information. We need the fuzzy AHP method for these reasons.

Fuzzy AHP is the extended version of classical AHP method. It was first developed by Laarhoven and Pedrycz. ${ }^{51}$ The most important problem of the method is related to the possibility of obtaining a normal and convex fuzzy number. The other problem of the method is that it requires cumbersome calculations. Buckley ${ }^{44}$ used the geometrical mean method to produce fuzzy values. Chang ${ }^{57}$ proposed a new approach involving triangular fuzzy number usage and extent analysis method for synthetic extent values of pair-wise comparisons. Cheng ${ }^{58}$ proposed a new algorithm for evaluating naval tactical missile systems by the fuzzy analytical process.

There has been lots of fuzzy AHP methods used in the literature. In this paper, the method of modified AHP method proposed by Zeng et al. ${ }^{29}$ will be used. In the following, the steps of the method are given ${ }^{29}$
Step 1. Measure evaluation factors in the hierarchy: The group members making the assessments can use crisp numbers, linguistic terms, a range of numerical values and fuzzy numbers to represent their experience and judgment. If any member has enough information about the considered evaluation, he/she can use crisp numbers or intervals. If he/she does not have enough information, linguistic variables or fuzzy numbers can be used.

Step 2. Compare factors using pairwise comparisons: The members in the assessment group need to compare the criteria in the hierarchical structure using pairwise comparisons.

Step 3. Convert preferences into STFNs: STFNs are employed to convert experts' judgments into a universal format for the composition of group preferences. These expressions are described below: ${ }^{50}$

- A crisp number " $x$ " is converted to a STFN as $\tilde{A}=(x, x, x, x)$, (ie. $a=b=c=d=x)$,

- A linguistic term, "about $x$ ", is converted to a STFN as $\tilde{A}=(x-1, \mathrm{x}, \mathrm{x}, \mathrm{x}+1), \quad$ (ie. $a=x-1, \quad b=c=x, d=x+1)$,

- A range, the scale is likely between $(x, y)$, is converted to a STFN as $\tilde{A}=(x, x, y, y)$, (ie. $a=b=x, c=d=y)$,

- A triangular fuzzy number, $\tilde{T}=(x, y, z)$, is converted to a STFN as $\tilde{A}=(x, y, y, z)$ (ie. $a=x, b=c=y, d=z)$,

- If a decision maker cannot compare any two factors at all, then it is represented with $\tilde{A}=(0,0,0,0)$, (ie. $a=b=c=d=0$ ).

Step 4. Aggregate individual STFNs into group STFNs: In Step 3, we have individual experts' evaluations which are represented by STFNs. Then we must convert individual ones to group assessment. To perform this step, fuzzy weighted trapezoidal averaging operator is used.

$$
\tilde{S}_{i}=\tilde{S}_{i 1} \otimes c_{1} \oplus \tilde{S}_{i 2} \otimes c_{2} \oplus \ldots \oplus \tilde{S}_{i m} \otimes c_{m}
$$

where $\tilde{S}_{i}$ is the fuzzy aggregated score of the factor $i$, $\tilde{S}_{i 1}, \tilde{S}_{i 2}, \ldots ., \tilde{S}_{i m}$ are the STFN scores of the factor $i$ measured by $m$ experts. $\otimes$ and $\oplus$ indicate the fuzzy multiplication operator and the fuzzy addition operator, respectively and $c_{1}, c_{2}, \ldots, c_{m}$ are defined as contribution factors $(\mathrm{CFs})$ which denote experts experiment and knowledge. 
To calculate the aggregation of the comparisons of the attributes, Eq. 4 is used.

$$
\tilde{a}_{i j}=\tilde{a}_{i j 1} \otimes c_{1} \oplus \tilde{a}_{i j 2} \otimes c_{2} \oplus \ldots \oplus \tilde{a}_{i j m} \otimes c_{m}
$$

where $\tilde{a}_{i j}$ is the aggregated fuzzy scale of attribute $i$ when compared to attribute $j$ for $i, j=1,2, \ldots, n$; $\tilde{a}_{i j 1}, \tilde{a}_{i j 2}, \ldots, \tilde{a}_{i j m}$ are the corresponding STFN scales of attribute $i$ comparing to attribute $j$ measured by experts $E_{1}, E_{2}, \ldots, E_{m}$, respectively.

Step 5. Defuzzify the STFN scale: The aim of this step is to convert the aggregated STFN scale to crisp values. To perform this step, Eq. (5) is used. $\tilde{a}_{i j}=\left(a_{i j}^{a}, a_{i j}^{b}, a_{i j}^{c}, a_{i j}^{d}\right)$ represents an aggregated STFN, where $a_{i j}$ represents a crisp value.

$$
a_{i j}=\frac{a_{i j}^{a}+2\left(a_{i j}^{b}+a_{i j}^{c}\right)+a_{i j}^{d}}{6}
$$

Step 6. Calculate the priority weights of factors: In order to calculate priority weights of the attributes, pairwise comparison matrix which involves $a_{i i}$ values is used. Assuming $A_{1}, A_{2}, \ldots, A_{n}$ represent a set of attributes in one group, pairwise comparisons between $A_{i}$ and $A_{j}$ yield an $n$-by- $n$ matrix defined by Eq. (6).

$$
A=a_{i j}=\begin{array}{cccccc} 
& A 1 & A_{2} & \ldots & A_{n} & \\
A_{1} & 1 & a_{12} & \ldots & a_{1 n} \\
A_{2} & 1 / a_{12} & 1 & \ldots & a_{2 n} \\
A_{3} & \ldots & \ldots & \ldots & \ldots & \\
A n & 1 / a_{1 n} & 1 / a_{2 n} & \ldots & 1 &
\end{array} \quad i, j=1,2, \ldots, n
$$

where $a_{i i}=1$ and $a_{j i}=1 / a_{i j}$

After creating pairwise comparisons matrix, the priority weights of factors can be calculated by using the arithmetic averaging method.

$$
w_{i}=\frac{1}{n} \sum_{j=1}^{n} \frac{a_{i j}}{\sum_{k=1}^{n} a_{k j}} i, j=1,2, \ldots, n .
$$

where $W_{i}$ is the section weight of $A_{i}$.

Assuming that $\mathrm{A}_{i}$ has $t$ upper sections at different level in the hierarchy, and $w_{\text {section }}^{(i)}$ is the section weight of the $i^{\text {th }}$ upper section which contains $A_{i}$ in the hierarchy, the final weight $w_{i}^{\prime}$ of $\mathrm{A}_{i}$ can be derived by

$$
w_{i}^{\prime}=w_{i} \times \prod_{i=1}^{t} w_{\text {group }}^{(i)}
$$

Step 7. Calculate final fuzzy scores: After all the $\tilde{S}_{i}$ and $w_{i}^{\prime}$ values are calculated, final scores FS can be calculated by,

$$
(\tilde{F S})=\sum_{i=1}^{n} \tilde{S}_{i} w_{i}^{\prime} \quad i=1,2, \ldots, n
$$

To determine the rank of final fuzzy scores, the area-based ranking method which was developed by Kahraman and Tolga ${ }^{59}$ is used.

A preference index that measures the possibility of one fuzzy number being greater than another is determined. This index, $I(w)$ is illustrated by ${ }^{59}$

$$
\mathrm{I}(\omega)=\frac{S_{\text {favor }}^{l}+S_{\text {favor }}^{r}+S_{\text {joint }}}{S_{a}+S_{b}}
$$

Using the $S$ areas shown in Fig 2, the preference index can be calculated by using Eq. 11

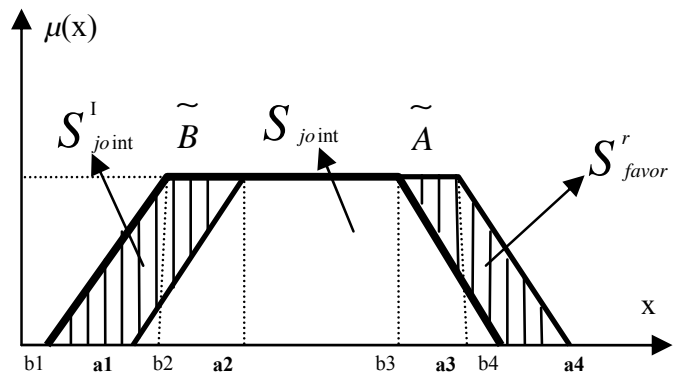

Fig. 2. Comparison of fuzzy numbers.

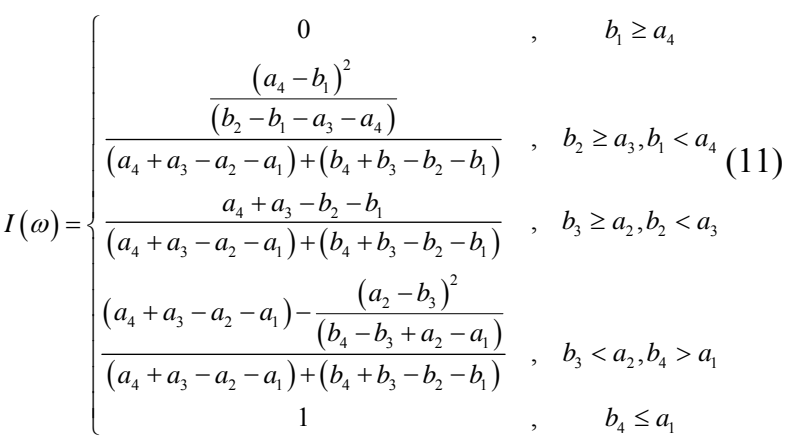

And the fuzzy preference relation $P_{K T}$ of the fuzzy numbers will be determined as following 


$$
P_{K T}(\tilde{A}, \widetilde{B})=\left\{\begin{array}{lc}
\tilde{A} \succ \widetilde{B} & \text { ifI }(\omega) \in(0.5,1] \\
\widetilde{A}=\tilde{B} & i f I(\omega)=0.5 \\
\widetilde{B} \succ \tilde{A} & \text { iff }(\omega) \in[0,0.5)
\end{array}\right.
$$

\section{Application}

In this section, supplier selection was applied for a firm which produces air-conditioners in Istanbul. The firm took into consideration three alternative suppliers, namely supplier A, supplier B, and supplier C. The firm would select the best supplier among these three suppliers. For the assessment of suppliers, three experts from purchasing department were assigned. Then CFs were assigned to the experts according to their background and experience: the first expert who was a purchasing manager was given 0.4 points, and the others were given 0.3 points each.

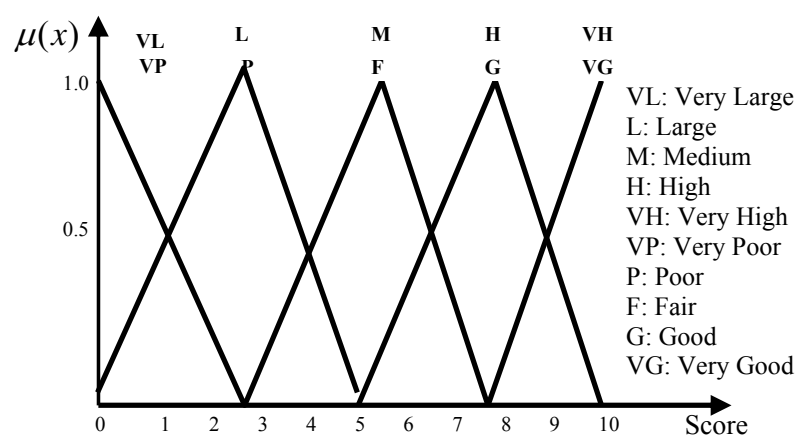

Fig. 3. Membership functions for linguistic evaluation

In order to select the best supplier, a four level hierarchy was established as in Figure 4. This hierarchy has five main attributes, 18 sub-attributes and three alternatives.

The experts evaluated each criterion using scoring system as in Figure 3. Each expert made an evaluation by using precise numerical values, a possible range of numerical values, a linguistic term, or a fuzzy number. Then evaluations were converted to STFNs as defined in Step 3. Table 2 indicates aggregated fuzzy scores which were established by the experts. Eq. (3) was used to obtain the aggregation of the scores.
For instance the aggregations of "On time delivery" under "Service "were calculated as;

$\widetilde{S}_{\text {time }}=(7,7,8,8) \otimes 0.40 \oplus(7,7,8,8) \otimes 0.30 \oplus(8,8,8,8) \otimes 0.30$

$\widetilde{S}_{\text {time }}=(7.30,7.30,8.00,8.00)$

Subsequently, the pairwise comparisons were calculated. The pairwise comparisons of the subattributes of "Quality" and the aggregated STFNs are shown in Table 3. For example, the STFN of the pairwise comparison between "Conformance to specification" and "Product reliability" was obtained as follows

$\tilde{a}_{12}=(3,3,4,4) \otimes 0.40 \oplus(3,3,4,4) \otimes 0.30 \oplus(2,2,3,3) \otimes 0.30$

$\tilde{a}_{12}=(2.70,2.70,3.70,3.70)$

Later, STFNs were converted to crisp values by using Eq. (5). The STFN of the pairwise comparison between "Conformance to specification" and "Product reliability" was defuzzified as below;

$a_{12}=\frac{2.70+2(2.70+3.70)+3.70}{6}$

$a_{12}=3.20$

After obtaining crisp values of attributes, pairwise matrices were established by using Eq. (6). For example the pairwise comparison matrix of "Quality" is given below.

$$
A_{\text {quality }}=\left[\begin{array}{lllll}
1.0000 & 3.2000 & 5.0000 & 1.9500 & 6.4000 \\
0.3125 & 1.0000 & 2.5500 & 0.2000 & 4.8000 \\
0.2000 & 0.3922 & 1.0000 & 0.1865 & 3.4667 \\
0.5128 & 5.0000 & 5.3619 & 1.0000 & 6.0000 \\
0.1563 & 0.2083 & 0.2885 & 0.1667 & 1.0000
\end{array}\right]
$$

After establishing the pairwise comparison matrix, arithmetic averaging method was used to calculate the priority weights of the attributes. For example the priority weights of "Quality" were calculated by using Eq. (7) as follows;

$w=\{0.3978,0.1406,0.0830,0.3370,0.4138\}$ 


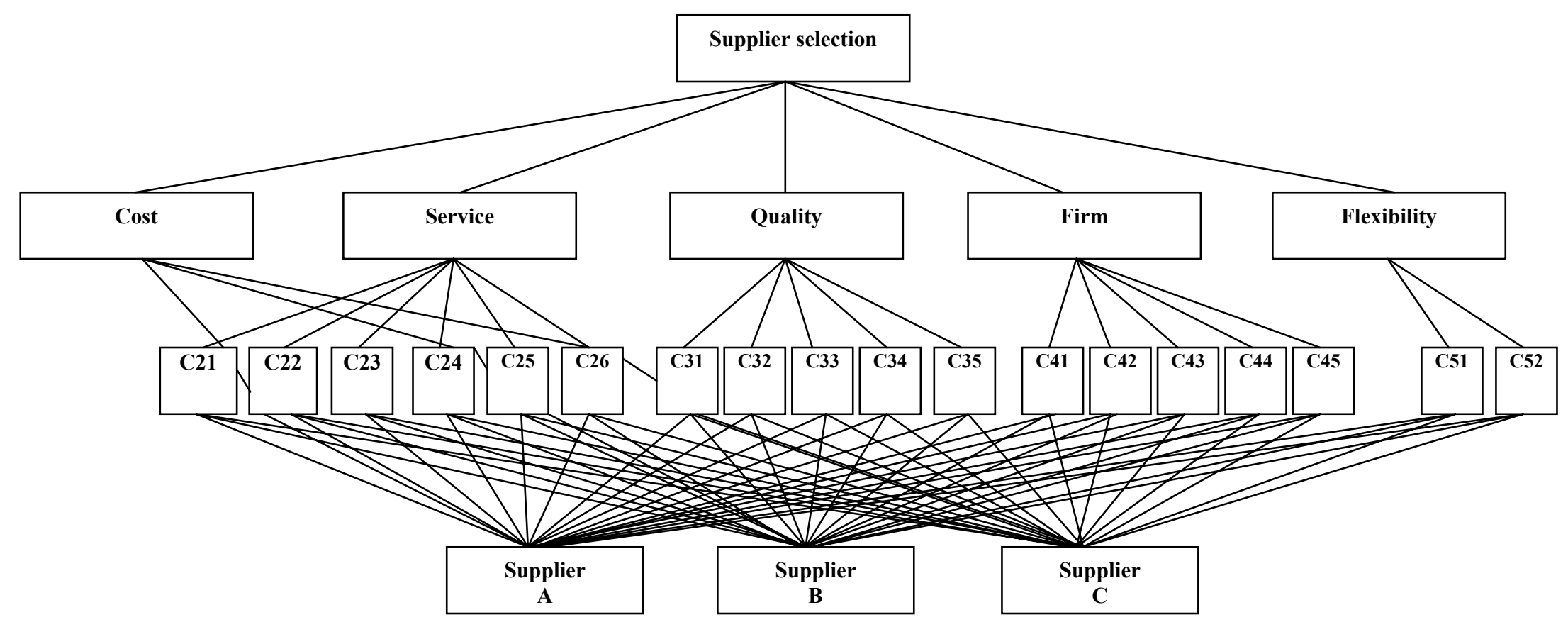

Fig. 4. The hierarchy for selection among the suppliers. 
Table 2 Scores and converted STFN supplier selection criteria for supplier A.

\begin{tabular}{|c|c|c|c|c|c|c|c|c|}
\hline & & \multicolumn{2}{|r|}{ E1 } & \multicolumn{2}{|c|}{ E2 } & \multicolumn{2}{|r|}{$\mathbf{E 3}$} & \multirow[b]{2}{*}{ Aggregated } \\
\hline & & Score & STFN & Score & STFN & Score & STFN & \\
\hline Cost & & A6 & $(5,6,6,7)$ & $6 \_7$ & $(6,6,7,7)$ & 6 & $(6,6,6,6)$ & $(5.6,6,6.3,6.7)$ \\
\hline \multirow{5}{*}{ Service } & Time & 7_8 & $(7,7,8,8)$ & 7_8 & $(7,7,8,8)$ & 8 & $(8,8,8,8)$ & $(7.3,7.3,8,8)$ \\
\hline & Warranty & $\mathrm{P}$ & $(0,2.5,2.5,5)$ & $3 \_3$ & $(3,3,3,3)$ & 3 & $(3,3,3,3)$ & $(1.8,2.8,2.8,3.8)$ \\
\hline & Repair & 4 & $(4,4,4,4)$ & 3_4 & $(3,3,4,4)$ & 4 & $(4,4,4,4)$ & $(3.7,3.7,4,4)$ \\
\hline & Information & $6 \_8$ & $(6,6,8,8)$ & 7_8 & $(7,7,8,8)$ & 8 & $(8,8,8,8)$ & $(6.9,6.9,8,8)$ \\
\hline & Storage & $\mathrm{P}$ & $(0,2.5,2.5,5)$ & $3 \_4$ & $(3,3,4,4)$ & 4 & $(4,4,4,4)$ & $(2.1,3.1,3.4,4.4)$ \\
\hline \multirow{5}{*}{ Quality } & Conformance & A8 & $(7,8,8,9)$ & 8_9 & $(8,8,9,9)$ & 9 & $(9,9,9,9)$ & $(7.9,8.3,8.6,9)$ \\
\hline & Reliability & $\mathrm{F}$ & $(2.5,5,57.5)$ & $3 \_4$ & $(3,3,4,4)$ & 3 & $(3,3,3,3)$ & $(2.8,3.8,4.1,5.1)$ \\
\hline & Techniques & 7_8 & $(7,7,8,8)$ & 8_9 & $(8,8,9,9)$ & 8 & $(8,8,8,8)$ & $(7.6,7.6,8.3,8.3)$ \\
\hline & Defect & A4.5 & $(3.5,4.5,4.5,5.5)$ & 4_4 & $(4,4,4,4)$ & 4 & $(4,4,4,4)$ & $(3.8,4.2,4.2,4.6)$ \\
\hline & Sensible & $\mathrm{F}$ & $(2.5,5,57.5$ & $4 \_6$ & $(4,4,6,6)$ & 4 & $(4,4,4,4)$ & $(3.4,4.4,5,6)$ \\
\hline \multirow{4}{*}{ Firm } & Experience & A4 & $(3,4,4,5)$ & $2 \_3$ & $(2,2,3,3)$ & 3 & $(3,3,3,3)$ & $(2.7,3.1,3.4,3.8)$ \\
\hline & Image & A5 & $(4,5,5,6)$ & $3 \_4$ & $(3,3,4,4)$ & 4 & $(4,4,4,4)$ & $(3.7,4.1,4.4,4.8)$ \\
\hline & location & VG & $(7.5,10,10,10)$ & 8_9 & $(8,8,9,9)$ & 9 & $(9,9,9,9)$ & $(8.1,9.1,9.4,9.4)$ \\
\hline & Financial & 4 & $(4,4,4,4)$ & $3 \_5$ & $(3,3,5,5)$ & 4 & $(4,4,4,4)$ & $(3.7,3.7,4.3,4.3)$ \\
\hline \multirow{2}{*}{ Flexibility } & Order volumes & G & $(5,7.5,7.5,10)$ & 7_8 & $(7,7,8,8)$ & 8 & $(8,8,8,8)$ & $(6.5,7.5,7.8,7.8)$ \\
\hline & Mix of ordered & 7 & $(7,7,7,7)$ & $6 \_8$ & $(6,6,8,8)$ & 7 & $(7,7,7,7)$ & $(6.7,6.77 .3,7.3)$ \\
\hline
\end{tabular}


Table 3 Fuzzy weights of sub-attributes of "Quality”.

\begin{tabular}{|c|c|c|c|c|c|c|c|c|c|c|c|c|c|c|c|}
\hline \multirow{6}{*}{$\begin{array}{c}\begin{array}{c}\text { Conformance } \\
\text { to }\end{array} \\
\text { Specification } \\
\end{array}$} & \multicolumn{3}{|c|}{$\begin{array}{c}\text { Conformance to } \\
\text { Specification } \\
\end{array}$} & \multicolumn{3}{|c|}{ Product Reliability } & \multicolumn{3}{|c|}{ Quality Assessment Tecniques } & \multicolumn{3}{|c|}{ Rate of Defect Product } & \multicolumn{3}{|c|}{ Sensible Quality } \\
\hline & \multirow{2}{*}{$\begin{array}{l}\text { Experts } \\
\text { E1 }\end{array}$} & \multirow[t]{2}{*}{ Scale } & \multirow[t]{2}{*}{ STFN } & \multicolumn{2}{|c|}{ Scale } & \multirow{2}{*}{$\frac{\text { STFN }}{(3,3,4,4)}$} & \multicolumn{2}{|c|}{ Scale } & \multirow{2}{*}{$\frac{\text { STFN }}{(5,5,5,5)}$} & \multicolumn{2}{|c|}{ Scale } & \multirow{2}{*}{$\frac{\text { STFN }}{(1,1,2,2)}$} & \multicolumn{2}{|c|}{ Scale } & \multirow{2}{*}{$\frac{\text { STFN }}{(7,7,7,7)}$} \\
\hline & & & & 3.00 & 4.00 & & 5.00 & 5.00 & & 1.00 & 2.00 & & 7.00 & 7.00 & \\
\hline & $\mathrm{E} 2$ & & & 3.00 & 4.00 & $(3,3,4,4)$ & 4.00 & 6.00 & $(4,4,6,6)$ & 2.00 & 2.00 & $(2,2,2,2)$ & 6.00 & 6.00 & $(6,6,6,6)$ \\
\hline & E3 & & & 2.00 & 3.00 & $(2,2,3,3)$ & 5.00 & 6.00 & $(5,5,6,6)$ & 2.00 & 3.00 & $(2,2,3,3)$ & 6.00 & 6.00 & $(6,6,6,6)$ \\
\hline & Aggregation & & 1.00 & & & $(2.70,2.70,3.70,3.70)$ & & & $(4.70,4.70,5.30,5.30)$ & & & $(1.6,1.6,2.3,2.3)$ & & & $(6.4,6.4,6.4,6.4)$ \\
\hline \multirow{4}{*}{$\begin{array}{c}\text { Product } \\
\text { Reliability }\end{array}$} & E1 & & & & & & 3.00 & 3.00 & $(3,3,3,3)$ & 0.20 & 0.20 & $(0.20,0.20,0.20,0.20)$ & 4.00 & 5.00 & $(4,4,5,5)$ \\
\hline & E2 & & & & & & 2.00 & 2.00 & $(2,2,2,2)$ & 0.20 & 0.20 & $(0.20,0.20,0.20,0.20)$ & 5.00 & 5.00 & $(5,5,5,5)$ \\
\hline & E3 & & & & & & 2.00 & 3.00 & $(2,2,3,3)$ & 0.20 & 0.20 & $(0.20,0.20,0.20,0.20)$ & 5.00 & 5.00 & $(5,5,5,5)$ \\
\hline & Aggregation & & & & & 1.00 & & & $(2.4,2.4,2.7,2.7)$ & & & $(0.20,0.20,0.20,0.20)$ & & & $(4.6,4.6,5.5)$ \\
\hline \multirow{4}{*}{$\begin{array}{c}\text { Quality } \\
\text { Assessment } \\
\text { Techniques }\end{array}$} & E1 & & & & & & & & & 0.20 & 0.20 & $(0.20,0.20,0.20,0.20)$ & 1.00 & 3.00 & $(1,1,3,3)$ \\
\hline & E2 & & & & & & & & & 0.17 & 0.17 & $(0.17,0.17,0.17,0.17)$ & 2.00 & 2.00 & $(3,3,4,4)$ \\
\hline & E3 & & & & & & & & & 0.17 & 0.20 & $(0.17,0.17,0.20,0.20)$ & 2.00 & 2.00 & $(3,3,3,3)$ \\
\hline & Aggregation & & & & & & & & 1.00 & & & $(0.182,0.82,0.191,0.191)$ & & & $(1.6,1.6,2.4,2.4)$ \\
\hline \multirow{4}{*}{$\begin{array}{c}\text { Rate of } \\
\text { Defect } \\
\text { Product }\end{array}$} & E1 & & & & & & & & & & & & 5.00 & 5.00 & $(5,5,5,5)$ \\
\hline & E2 & & & & & & & & & & & & 3.00 & 6.00 & $(3,3,6,6)$ \\
\hline & E3 & & & & & & & & & & & & 4.00 & 6.00 & $(4,4,6,6)$ \\
\hline & Aggregation & & & & & & & & & & & 1.00 & & & $(4.1,4.1,5.6,5.6)$ \\
\hline \multirow{4}{*}{$\begin{array}{l}\text { Sensible } \\
\text { Quality }\end{array}$} & E1 & & & & & & & & & & & & & & \\
\hline & E2 & & & & & & & & & & & & & & \\
\hline & E3 & & & & & & & & & & & & & & \\
\hline & Aggregation & & & & & & & & & & & & & & 1.00 \\
\hline
\end{tabular}


By using Eq. (8), $w_{i}$ values which are the final weights of the attributes were calculated. Then the $\widetilde{F S}$ of supplier A was calculated by using Eq. (9)

$$
F S_{A}=\{8.4055,9.0568,9.5297,10.1527\}
$$

Other suppliers' scores were calculated by the modified AHP method and given in Table 4.

The trapezoidal fuzzy numbers of suppliers will be ranked by using the fuzzy ranking method which was explained in Section 4. The ranking results are shown in Table 5. The ranking of alternatives is found as follows: \{Supplier C, Supplier A, Supplier B )

Table 4. Suppliers' scores.

\begin{tabular}{|c|c|}
\hline Supplier Firm & $\widetilde{F S}$ values \\
\hline Supplier A & $(8.40,9.05,9.52,10.15)$ \\
\hline Supplier B & $(6.17,6.82,7.35,7.99)$ \\
\hline Supplier C & $(8.44,9.20,9.72,10.37)$ \\
\hline
\end{tabular}

Table 5. The ranking of alternatives.

\begin{tabular}{|c|c|c|}
\hline Suppliers & $\mathbf{I}(\boldsymbol{\omega})$ & Comparison \\
\hline A-B & 1 & A $>$ B \\
\hline A-C & 0.56424 & C $>$ A \\
\hline C-B & 1 & C $>$ B \\
\hline
\end{tabular}

\section{Sensitivity Analysis}

In this section a sensitivity analysis was performed. Different weights were assigned to contribution factors of experts and were analyzed to observe how much it would influence the final scores of alternatives. In the first case, the experts' weights are 0.4, 0.3, and 0.3, respectively and the final scores are obtained as $F S_{A}=9.28, F S_{B}=7.08, F S_{C}=9.44$ after defuzzfication. In the second case the experts' weights are assigned as $0.4,0.5$, and 0.1 , respectively and the final scores are calculated to be $F S_{A}=9.37, F S_{B}=6.90, F S_{C}=9.33$ after defuzzfication. In the third case the experts' weights are assigned as $0.2,0.1$, and 0.7 , respectively and the final scores are calculated as follows: $F S_{A}=9.20, F S_{B}=7.06, F S_{C}=10.04$. It is seen that although the experts' weights are changed significantly, Supplier B always takes the third order.
On the other hand Supplier A takes the second order when the second expert's weight is significantly increased. Figure 5 illustrates the results of sensitivity analysis.

\section{Conclusion}

Supplier selection is a critical decision making problem for the firm in order to establish an efficient supply chain network. It is important not only for the firms but also for the suppliers to improve their performance.

We proposed a general framework for any firm to utilize in supplier selection. In this study, the modified fuzzy model is proposed as a tool for selecting the best supplier. The fuzzy AHP enables decisionmakers to use precise numerical values, linguistic terms, range of numerical values, or fuzzy numbers. Flexibility of using this assessment scale renders this method better than the other fuzzy AHP methods. The modified fuzzy AHP can serve to capture the imprecision of human thought in supplier selection.

As for future work other fuzzy multicriteria approaches like fuzzy TOPSIS, fuzzy ELECTRE, fuzzy ORESTE, fuzzy PROMETHEE, or fuzzy MAUT can be used in supplier selection and can be compared with the finding of the current study.

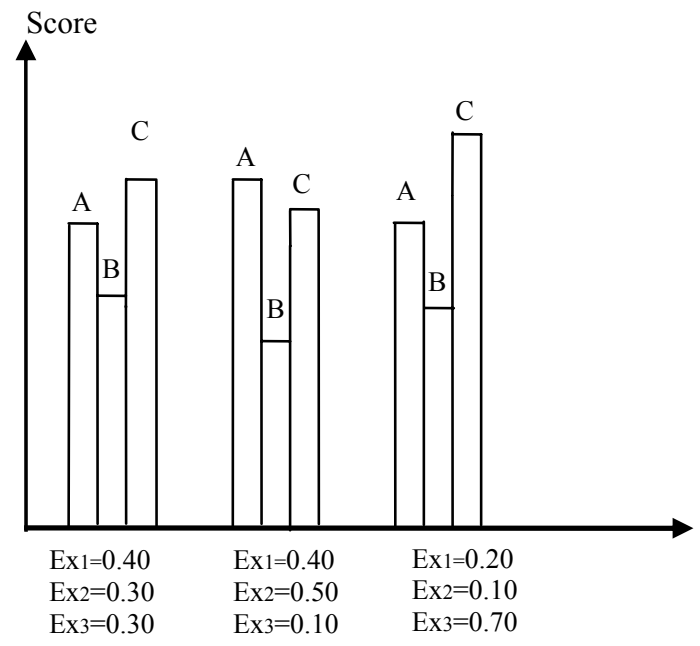

Fig. 5. Sensitivity analysis results. 


\section{References}

1. S. H. Amin and J. Razmi, An integrated fuzzy model for supplier management: A case study of ISP selection and evaluation, Expert Systems with Application 36 (2009) 8639-8648.

2. F. T. S. Chan, N. Kumar, M. K. Tiwari, H. C. W. Lau, and K. L. Choy, Global supplier selection: a fuzzy-AHP approach, International Journal of Production Research 36(14) (2008) 3825-3857.

3. J. Razmi , H. Rafiei, and M. Hashemi, Designing a decision support system to evaluate and select suppliers using fuzzy analytic network process, Computers \& Industrial Engineering 54(7) (2009) 1282-1290

4. D. Wu, Supplier selection: A hybrid model using DEA, decision tree and neural network, Expert Systems with Applications 36 (2009) 9105-9112.

5. O. C. T. Onesime, X. Xiaofei, and Z. Dechen, A decision support system for supplier selection process, International Journal of Information Technology \& Decision Making 3(3) (2004) 453-470.

6. H. Min, International Supplier Selection: A multi attribute utility approach, International Journal of Physical Distribution and Logistics Management 24(5) (2009) 24-33.

7. L. Boer, L. Wegen, and J. Telgen, Outranking methods in support of supplier selection, European Journal of Purchasing \& Supply Management 4 (1998) 109- 118.

8. S.H. Ghodsypour and C. O'Brien, A decision support system for supplier selection using an integrated analytic hierarchy process and linear programming, International Journal of Production Economics 56 (1998) 199-212.

9. B. Karpak and E. Kumcu, and R. R. Kasuganti, Purchasing materials in the supply chain: Managing a multi-objective task, European Journal Of Purchasing And Supply Management 7(3) (2001) 209-216.

10. S. Talluri and R. Narasimhan, Vendor evaluation with performance variability: A max-min approach, European Journal of Operational Research 146(3) (2003) 543- 552.

11. E. Oz and O. F. Baykoc, Tedarikci secimi problemine karar teorisi destekli uzman sistem yaklasimi, Gazi Üniv. Müh. Mim. Fak. Dergisi 19(3) (2004) 275-286.

12. I. H. Cedimoğlu and T. Tunacan, Örüntü tanima sistemiyle tedarikci secimi, XXIV. Operation research/Industrial Engineering International Conference (Gaziantep- Adana, Turkey, 2004).

13. R. Narasimhan, S. Talluri, and S.K. Mahapatra, Multiproduct, multicriteria model for supplier selection with product life-cycle considerations, Decision Sciences 37(4) (2006) 577-603.

14. G.H. Hong, S.C. Park, D.S. Jang, and H.M. Rho, An effective supplier selection method for constructing a competitive supply-relationship, Expert Systems with Applications 28(4) (2005) 629-639.

15. R. F. Saen, A decision model for selecting technology suppliers in the presence of nondiscretionary factors, Applied Mathematics and Computation 181(2) (2006) 1609-1615.
16. F. E. Boran, S. Genc, M. Kurt, and D. Akay, A multi-criteria intuitionistic fuzzy group decision making for supplier selection with TOPSIS method, Expert Systems With Applications 36 (2009) 11363-11368.

17. M. Dağdeviren and E. Eraslan, PROMETHEE siralama yöntemi ile tedarikçi seçimi, Gazi Üniv. Müh. Mim. Fak. Dergisi 23(1) (2008) 69-75.

18. C. Gencer, D. Gürpınar, Analytic network process in supplier selection: A case study in an electronic firm, Applied Mathematical Modeling 31 (2007) 2475-2486.

19. Z. Liao and J. Rittscher, A multi-objective supplier selection model under stochastic demand conditions, International Journal of Production Economics 105(1) (2007) 150-159.

20. W. Junyan, Z. Ruiqing, and T. Wansheng, Fuzzy programming models for vendor selection problem in a supply chain, Tsinghua Science And Technology 13(1) (2008) 106-111.

21. F. Faez, S. H. Ghodsypour, and C.O. O'Brien, Vendor selection and order allocation using an integrated fuzzy casebased reasoning and mathematical programming model, International Journal of Production Economics 121(2) (2007) 395-408.

22. H.S. Ha and R.A Krishnan, Hybrid approach to supplier selection for the maintenance of a competitive supply chain, Expert Systems with Applications 34(2) (2008) 1303-1311.

23. W. Xia and Z. Wu, Supplier selection with multiple criteria in volume discount environments, International Journal of Management Science 35(5) (2007) 494-504.

24. F.T.S. Chan, N. Kumar, M.K. Tiwari, H.C.W. Lau, and K.L. Choy, Global Supplier Selection: A Fuzzy-AHP Approach, International Journal of Production Research 46(14) (2008) 3825-3857.

25. J. Hou and D. Su, EJB-MVC Oriented supplier selection system for mass customization, Journal of Manufacturing Technology Management 18(1) (2007) 54- 71.

26. C. Kahraman, U. Cebeci, and Z. Ulukan, Multicriteria supplier selection using fuzzy AHP, Logistics Information Management 16(6) (2003), 382-394.

27. H. Cercioğlu, M.E. Baysal, B. Toklu, and A. Ercengiz, tedarikci seciminde Dempster-Shafer AHP modeli, XXIV. Operation research/Industrial Engineering International Conference (Gaziantep- Adana, Turkey, 2004).

28. C. Kubat and B. Yüce, Supplier Selection with Genetic Algorithm and Fuzzy AHP , Proceedings of 5th International Symposium on Intelligent Manufacturing Systems ( Sakarya, Turkey, 2006), pp.1382-1401.

29. J. Zeng, M. An and N.J. Smith, Application of a fuzzy based decision making methodology to construction project risk assessment. International Journal of Project Management 25 (2007) 589-600.

30. R.L. Nydick and R.P. Hill, Using The Analytic hierarchy process to structure the supplier selection procedure, International Journal of Purchasing \& Materials Management 28(2) (1992) 31-36.

31. V. Albino and A.C. Garavelli, A Neural network application to subcontractor rating in construction firms, Pergamon 
International Journal of Project Management 16(1) (1998), 9-14.

32. I.H. Lee, A fuzzy supplier selection model with the consideration of benefits, opportunities, costs and risks, Expert Systems with Applications: An International Journal 36(2) (2009) 2879-2893.

33. N. Bharadwaj, Investigating the decision criteria used in electronic components procurement, Industrial Marketing Management 33(4) (2004) 317-323.

34. H.S. Hwang, C. Moon, C. Chuang, and M. Goan, , Supplier selection and planning model using AHP, International Journal of the Information Systems for Logistics and Management 1(1) (2005) 47-53

35. R. Verma and M.E. Pullman, An analysis of the supplier selection process, International Journal of Management Science 26(6) (1998) 739- 50.

36. S.C. Ting, A Multi-Objective Approach To Purchasing decision and supplier selection in the supply chain, Proceedings of The 17th Int. Conf. on Multiple Criteria Decision Analysis ( Canada, 2004)

37. D.R. Lehmann and J. O'Shaughnessy, Difference in attribute importance for different industrial products, Journal of Marketing 38(1) (1974) 36-42.

38. G. Kanan and A.N. Haq, Analysis of interactions of criteria and sub-criteria for the selection of supplier in the built-inorder supply chain environment, International Journal of Production Research 45(17) (2007) 3831-3852

39. V. Jayaraman, R. Srivastava, and W.C. Benton, supplier selection order quantity allocation a comprehensive model, The Journal of Supply Chain Management 35(2) (1999) 5059.

40. W. Siying, Z. Jinlong, and L. Zhicheng, A Supplier selection system using a neural network, Proceedings of IEEE International Conference on Intelligent Processing Systems (Newyork, 1997) 468-471 1997.

41. C.A. Weber, J. R. Current, and W.C. Benton, Vendor selection criteria and methods, European Journal of Operational Research 50(1) (1997) 2-18.

42. W. Thanaraksakul and B. Phruksaphanrat, Supplier evaluation framework based on balanced scorecard with integrated corporate social responsibility perspective, Proceedings of the International MultiConference of Engineers and Computer Scientists (Hon Kong, 2009 ), pp. 978-988.

43. S. Zaim, M. Sevkli, and M. Tarim, Fuzzy analytic hierarchy based approach for supplier selection, Journal of Euromarketing 12(3) (2003) 147-176.

44. N. Stavropolous, Suppliers in the new economy, The Telecommunications Journal of Australia 50(4) (2000) 2729.

45. S.B. Barla, A case study of supplier selection for lean supply by using a mathematical model, Logistics Information Management 16(6) (2003) 451-459.
46. F. T. S. Chan and H. K. Chan, Development of the supplier selection model; A case study in the advanced technology industry, Proc. Institution Mechanical Engineers 218 (2004) 1807-1824.

47. L. Zadeh,. Fuzzy sets. Information Control 8(3) (1965), 338353.

48. S. Chen and C. Hwang, Fuzzy multiattribute decision making methods and application, (Springer-Verlag, New York, 1992).

49. C. Huanga, P. Chub, and Y. Chiang, A fuzzy AHP application in government-sponsored R\&D project selection, Omega 36 (2008) 1038-1052

50. C. Kahraman, A. Beskese, and I. Kaya, Selection among ERP outsourcing alternatives using a fuzzy multicriteria decision making methodology, International Journal of Production Research,48(2) (2009) 547-566.

51. P.J.M. Laarhoven and W. Pedrycz, A fuzzy extension of Saaty's priority theory, Fuzzy Set Systems. 11 (1983) 229-41.

52. J.J. Buckley Fuzzy eigenvalues and input-output analysis, Fuzzy Set Systems 34 (1990) 187-95.

53. D. Dubois and H. Prade, Operation on fuzzy numbers International Journal of Systems Science 9(6) 1978 613-626.

54. T.L. Saaty, The Analytic Hierarchy Process, (McGraw- Hill, New York, 1980).

55. M. Dagdeviren, S. Yavuz, and N. Kilinc, Weapon selection using the AHP and TOPSIS methods under fuzzy environment, Expert Systems with Applications 36 (2009) $8143-8151$.

56. S. Omkarprasad, Vaidya, and K. Sushil, Analytic hierarchy process: An overview of applications, Europe Journal Operational Research 169 (2006) 1-29.

57. D.Y. Chang, Applications of the extent analysis method on fuzzy AHP. European Journal of Operational Research, 95 (1996) 649-655.

58. C.H. Cheng, Evaluating naval tactical missile systems by fuzzy AHP based on the grade value of membership function, European Journal of Operational Research 96 (1996) 343350.

59. C. Kahraman and A.C Tolga, An alternative ranking approach and its usage in multicriteria decision- making, International Journal of Computational Intelligence Systems , 2(3) 2009 219-235. 